\title{
Vaso-glial connections in the rabbit retina
}

\author{
BRENDA TRIPATHI AND NORMAN ASHTON \\ Department of Pathology, Institute of Ophthalmology, University of London
}

The anatomy and development of the retinal vasculature of the rabbit have been described by numerous workers in the past (His, I880; Langenbacher, I880; Bruns, I 882; Schultze, I892; Fuchs, 1905; Eisler, 1930; Kuwabara and Cogan, 1960; Mutlu and Leopold, 1964; Agarwal, Singh, and Dayal, 1966). Particularly valuable accounts of recent years are those of Michaelson, 1954; Rohen, I954; Hyvärinen, 1967. Although there has been considerable controversy, it is now generally agreed that the vessels are confined to the medullated nerve fibre layers, which extend horizontally as wing-shaped areas on either side of the disc, and, apart from deep capillary branches at the disc margin and deep loop capillaries arising from the inner two-thirds of the vascular complexes, it is thought that they lie entirely on the surface of the retina, upon or in close relation to the inner limiting membrane. Two modifications of this view were briefly referred to in recent papers: Rohen (1954) stated that the "larger branches of the vessels are connected by a few connective tissue fibres to the retina", and Hyvärinen (1967) illustrated what he believed to be a sheath of internal limiting membrane around a capillary. There appears, however, to be no previous account in the literature of the exact ultrastructural relationship of the vessels to the retina nor of the remarkable glial tufts which extend out of the retina, at frequent and irregular intervals, to embrace and anchor the superficial vessels to the retinal surface. We have recently observed these structures in an electron microscopical study of the rabbit retina and here present an account of our findings.

\section{Methods and material}

The eye of a young adult rabbit ( 13 weeks old) was enucleated under Nembutal anaesthesia and was fixed immediately by cutting open at the ora serrata in I per cent. isotonic osmium tetroxide solution at $\mathrm{pH} 7 \cdot 4$. The zone of the retinal vascular complex was dissected out and embedded in Araldite. Serial thick sections $(I-2 \mu)$, perpendicular to the plane of the retina, were cut from the tip of the vascular complex to the optic disc and were stained with toluidine blue for light microscopy. Thin sections for electron microscopy were cut from selected areas of the block and stained with uranyl acetate and lead citrate. Sections were examined and the electron micrographs taken with an AEI EM6 electron microscope.

This communication is dedicated to Prof. Dr. Josef Böck on the occasion of his 7oth birthday 


\section{Findings}

LIGHT MIGROSGOPY

In cross-sections the superficial vessels of the retinal vascular complex were found in three distinct locations:

(I) Lying free in the vitreous near to the retinal surface but having no contact with the internal limiting membrane (Fig. I).

(2) Lying near to or upon the surface of the internal limiting membrane, and in places adhering to or enwrapped by glial protrusions or tufts extending towards them from the nerve fibre layer of the retina (Figs $I$ and 2).

(3) Apparently lying just within the nerve fibre layer (Fig. 3).

\section{ULTRASTRUGTURE}

In the first group, illustrated in Fig. 4, the vessels are seen to possess a normal vascular architecture consisting of a lumen filled with plasma and blood corpuscles, an endothelial lining having tight junctions, and a tenuous basement membrane containing intramural pericytes (Ashton and Oliveira, I966); larger vessels also show one or two layers of muscle cells. They lie free within the vitreous surrounded by a condensation of vitreous fibrils which fuse with their basement membranes. At higher magnifications the vitreous fibrils can be seen widely separating the cell membrane and basement membrane of the vessel from the basement membrane and plasma membrane of the glial cell, which together constitute the internal limiting membrane of the retina (Fig. 5). Occasionally vitreal cells are seen lying close to the vessels.

Vessels seen in sections of the second group show a similar structure, but their close approximation to the internal limiting membrane is now apparent. Occasionally, the vessels dip into the surface of the retina, their basement membranes lying in close contact with the internal limiting membrane which remains intact (Fig. 6). In other places, however, glial protrusions covered by internal limiting membrane extend into the vitreous to come in contact with the vessel wall (Fig. 7). At frequent but irregular intervals, sections show mushroom-like protrusions of glial tissue extending into the vitreous through narrow breaks in the internal limiting membrane, to enclasp and almost completely surround the vessel (Fig. 8), thus forming a firm adhesion to the retinal surface. These protruding glial cells sometimes possess basement membranes distinct from those of the vessels, but in other areas are devoid of basement membrane; their plasma membranes then abut directly onto vitreous or onto vascular basement membrane. The tufts show an internal structure comparable to the glial cells in the retina, with which their cytoplasm and intracellular fibrils are continuous (Figs 8 and 9). The latter are orientated in the long axis of the glial cells and are often condensed as they curve around the edge of the break in the internal limiting membrane (Fig. Io).

Sections of vessels in the third group, wherein vessels appear to lie within the inner nerve fibre layer, show at high magnification that they are not actually within the retina, but lie encupped in invaginations of the internal limiting membrane from which they are separated by a delicate layer of collagenous fibrils (Fig. I I).

\section{Discussion}

This electron microscopical study would seem to resolve completely the old controversy whether the superficial vessels of the rabbit retina lie within or upon the retinal surface. 


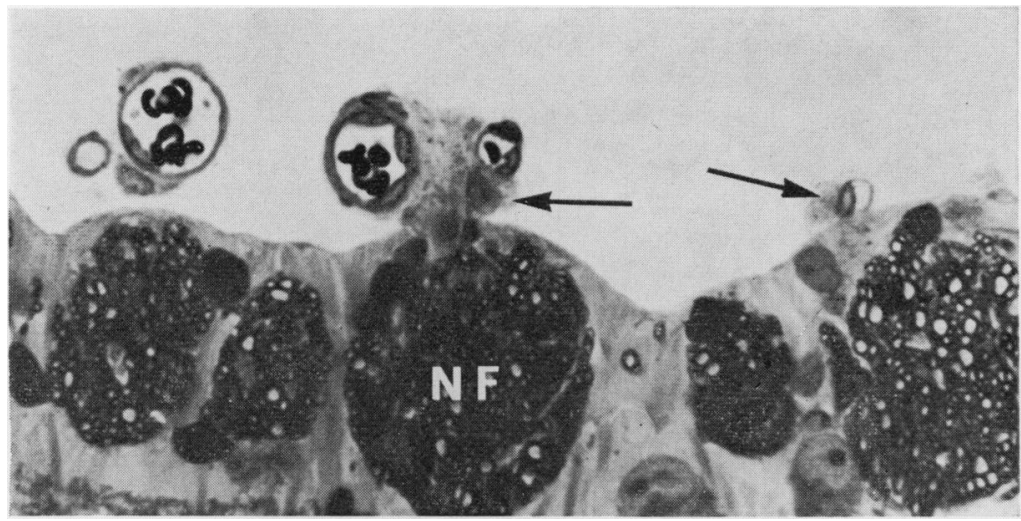

FIG. I Cross-section of superficial retinal vessels and medullated nerve fibre layer $(\mathcal{N F})$ of rabbit retina, showing vessels lying free in the vitreous (left) and others connected to the retina by glial tufts (arrows) $\times 53^{\circ}$

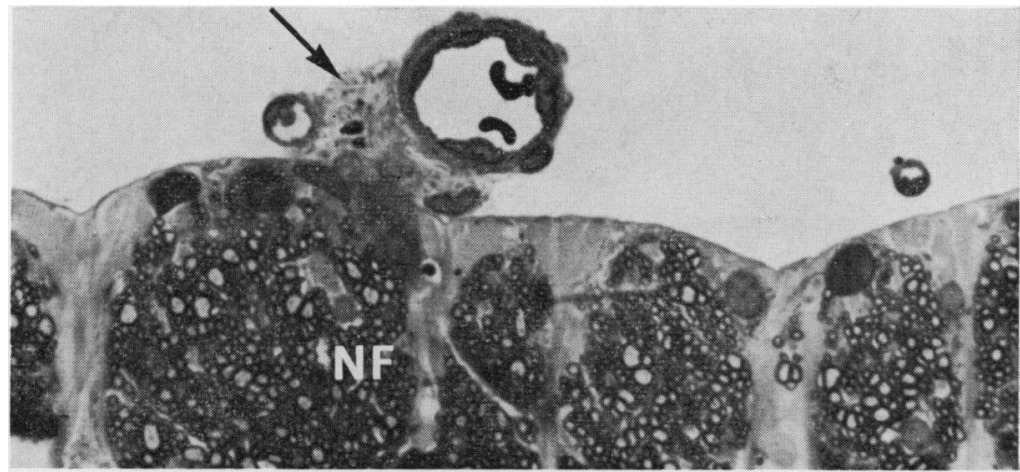

FIG. 2 Centrally two retinal vessels are connected to the retina by a glial tuft (arrow). On the right a capillary lies free in the vitreous. $\quad \times 660$

$\mathrm{NF}=$ Medullated nerve fibre layer

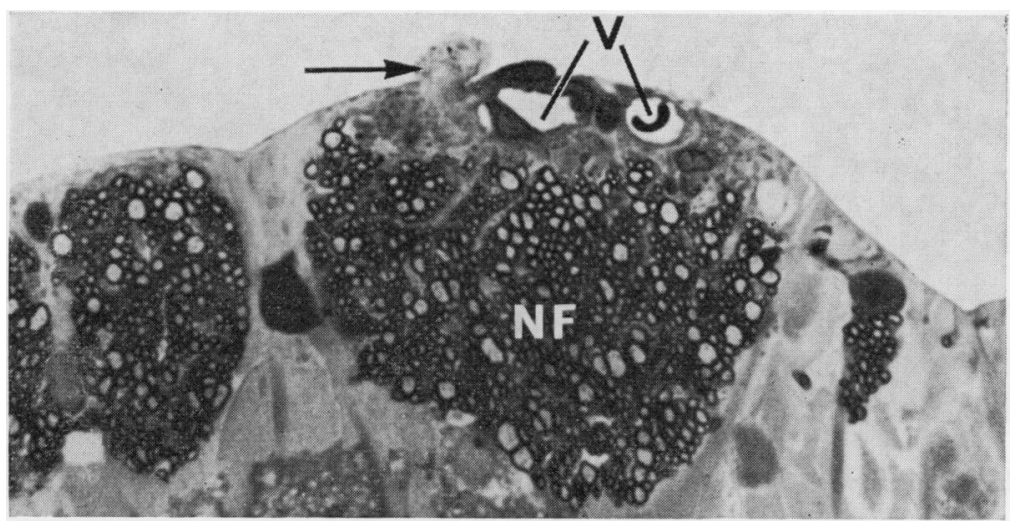

FIG. 3 Cross-section of retina, showing vessels (V) apparently lying within the inner nerve fibre layer $(\mathcal{N} F)$. Note also a protruding glial tuft (arrow). $\times 660$

Footnote: Figs I-3. Araldite sections. Toluidine blue stain 




F1G. 4 Electron micrograph, showing blood vessels lying free in the vitreous $\times 3,250$ (approx.)
$\mathrm{L}=$ lumen containing plasma and blood corpuscles
$\begin{array}{lc}\mathbf{E}=\text { endothelium } \quad \mathrm{P}=\text { pericyte } & \mathrm{VG}=\text { vitreal cell } \\ \mathrm{NF}=\text { nerve fibre layer of the retina } & \mathrm{MF}=\text { Müller fibres }\end{array}$ 


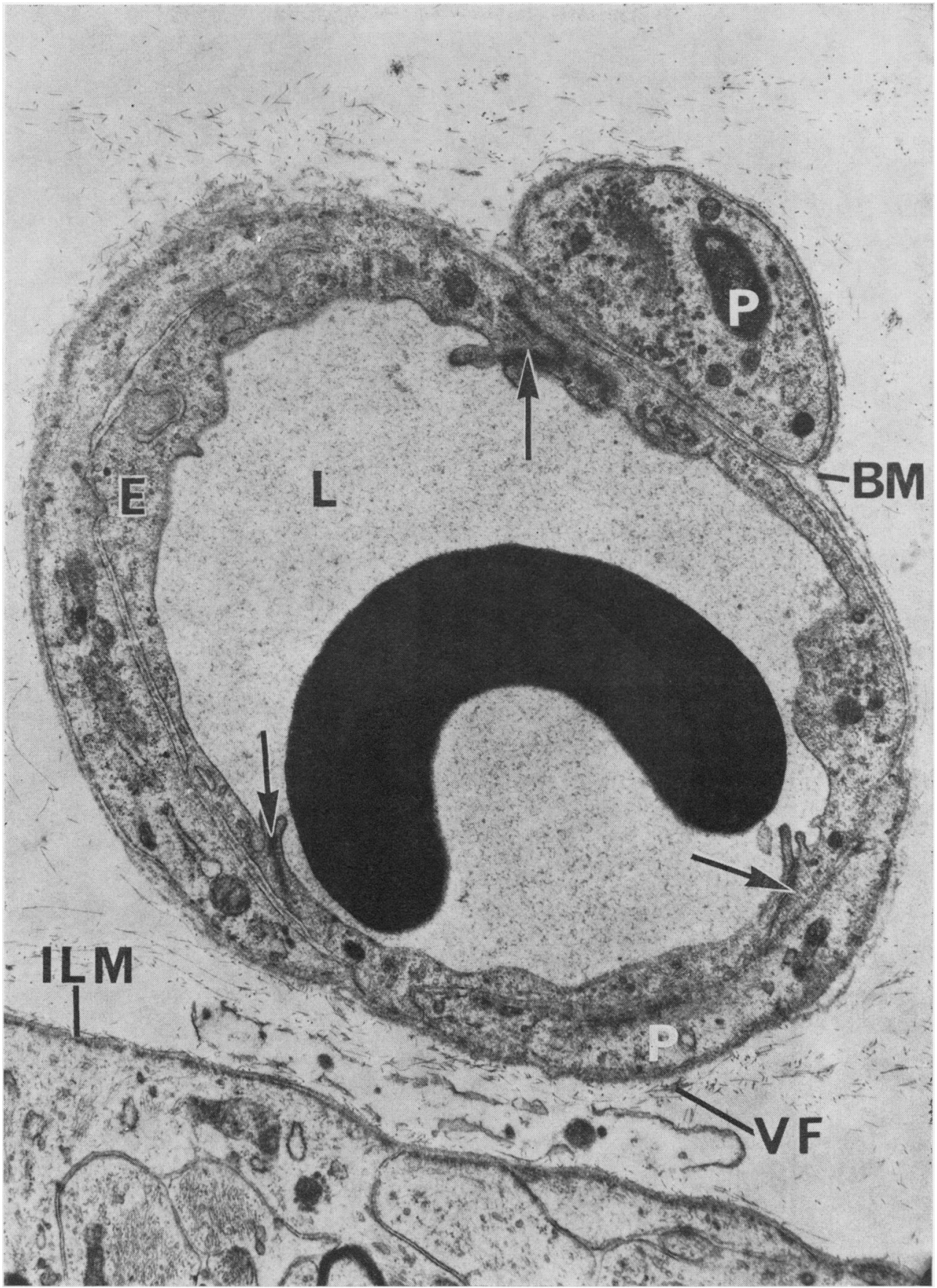

FIG. 5 Electron micrograph of a blood vessel lying free in vitreous but close to the internal limiting membrane $(I L M) . \times 16,000$

$\mathbf{L}=$ lumen $\quad \mathrm{E}=$ endothelium with cell junctions arrowed

$P=$ intramural pericyte

BM $=$ basement membiane of the blood vessel

$\mathrm{VF}=$ vitreous fibrils 


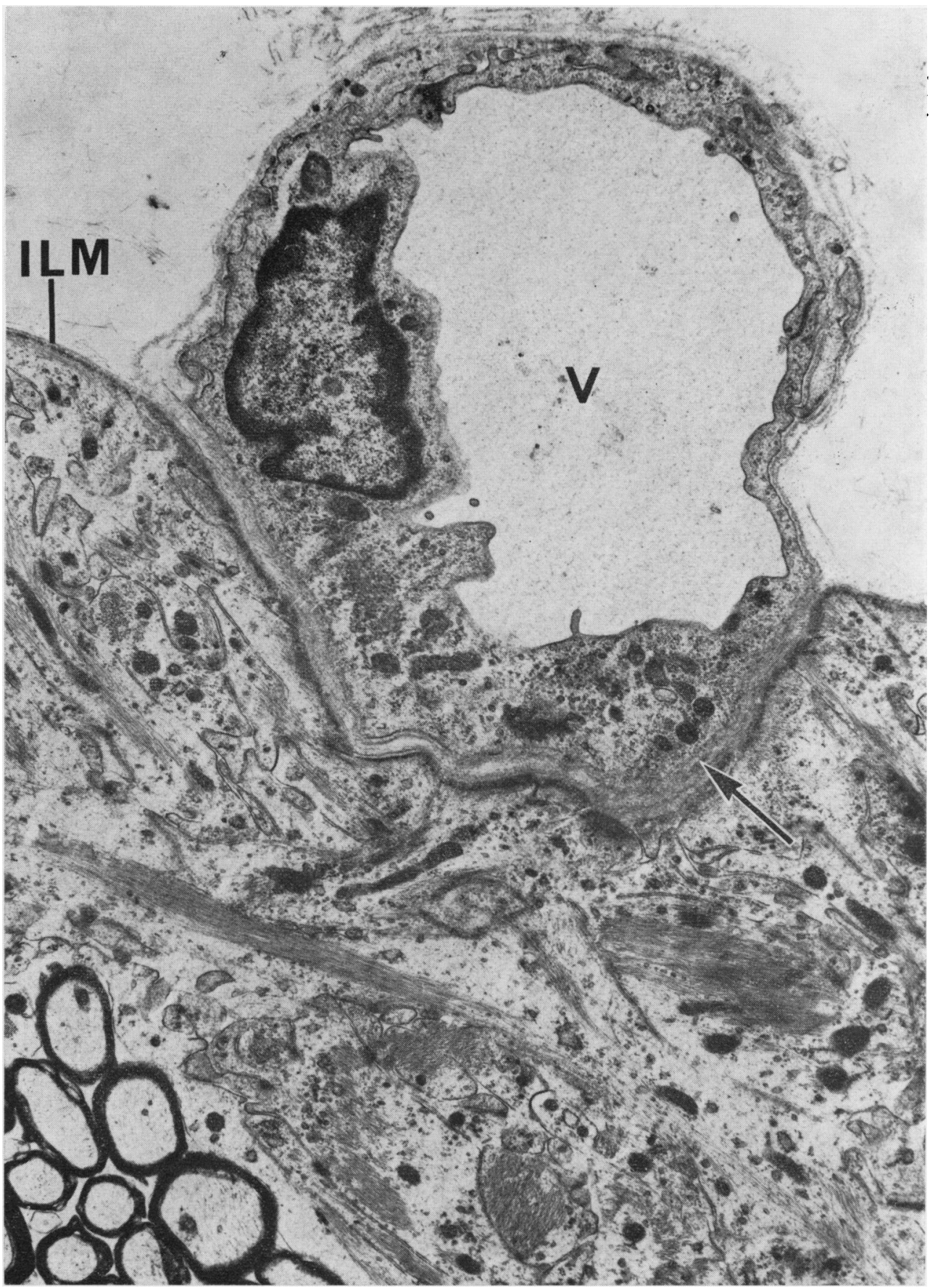

FIG. 6 Electron micrograph of a blood vessel $(V)$ dipping into the surface of the retina and indenting the internal limiting membrane (ILM). Note that the basement membrane in places appears to fuse with the internal limiting membrane (arrow) while in other places the two can be recognised distinctly. $\times$ I I, OOO 


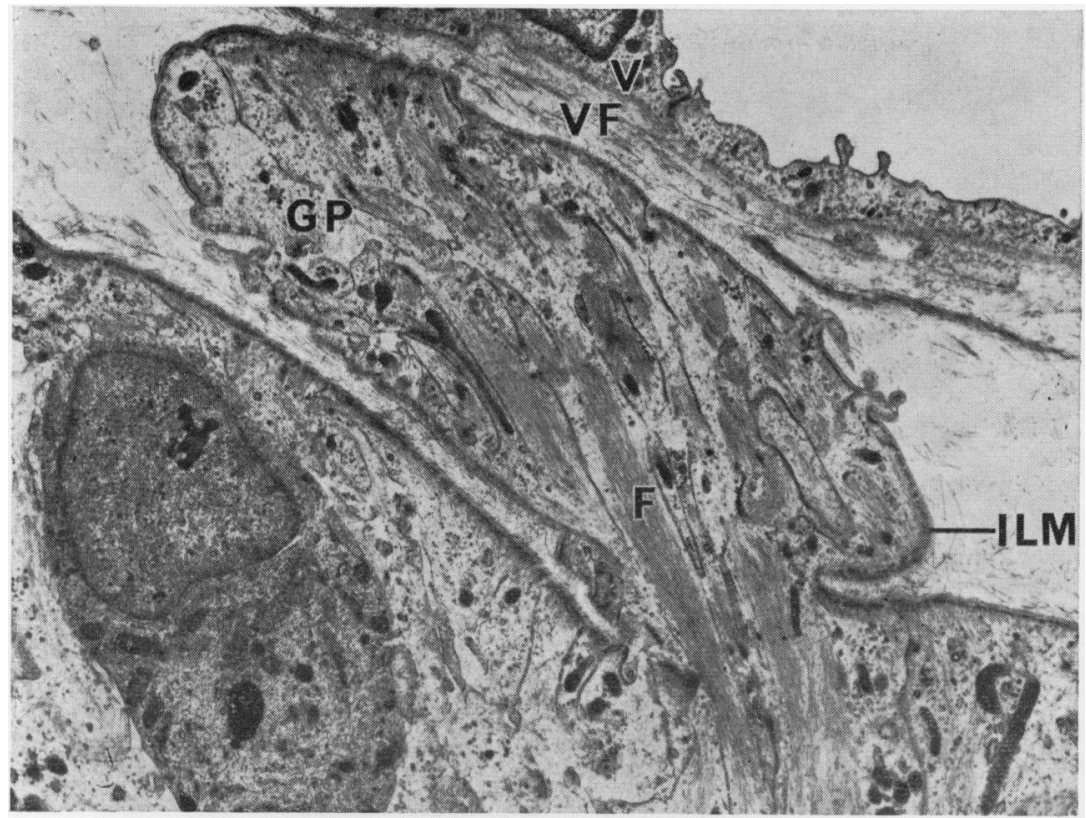

FIG. 7 Electron micrograph of a glial protrusion (GP) having a covering of internal limiting membrane (ILM) and coming in contact with the blood vessel $(V)$. Note the longitudinal arrangement of the intracellular fibrils $(F)$ extending through the narrow neck of the glial protrusion. $\quad \times 6,650$

$\mathrm{VF}=$ vitreous fibrils interposed between the internal limiting membrane covering the glial tuft and the basement membrane of the blood vessel

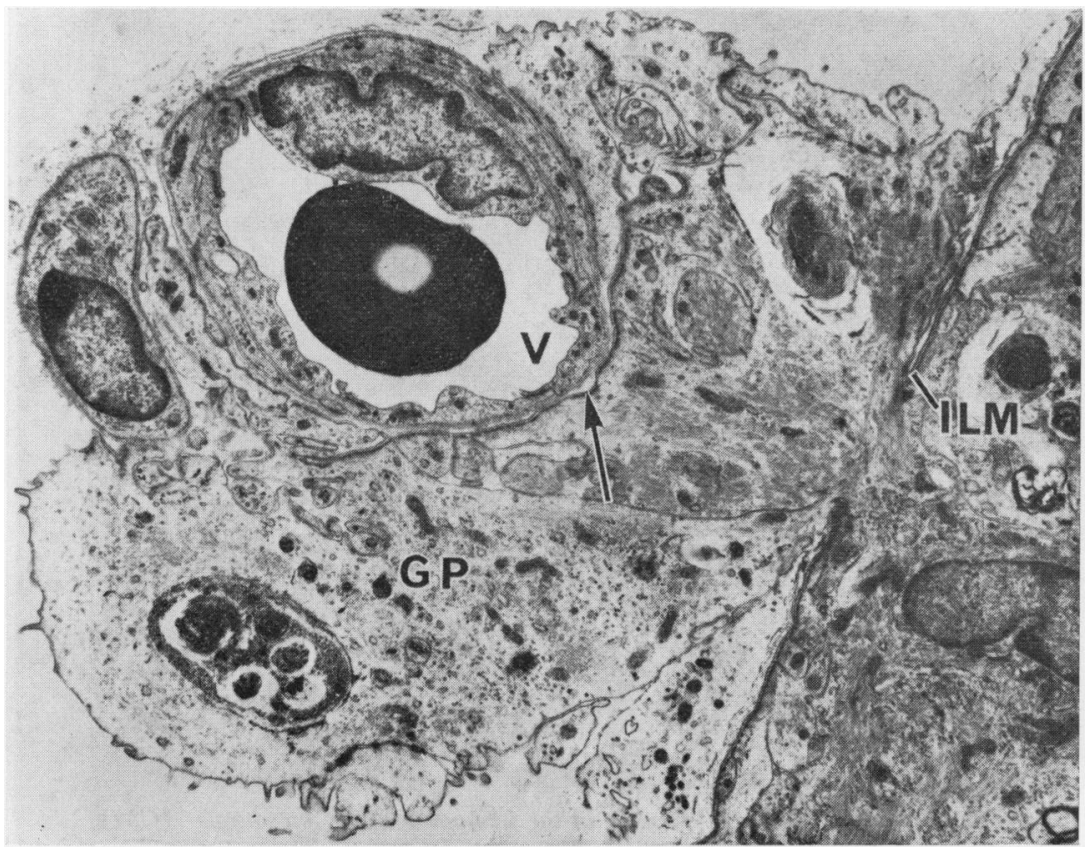

FIG. 8 Electron micrograph of a glial tuft $(G P)$ protruding through a narrow break in the internal limiting membrane (ILM) and enwrapping a blood vessel $(V)$. Note the remains of the internal limiting membrane (arrow) in contact with the basement membrane of the blood vessel. $\times 4,800$ 


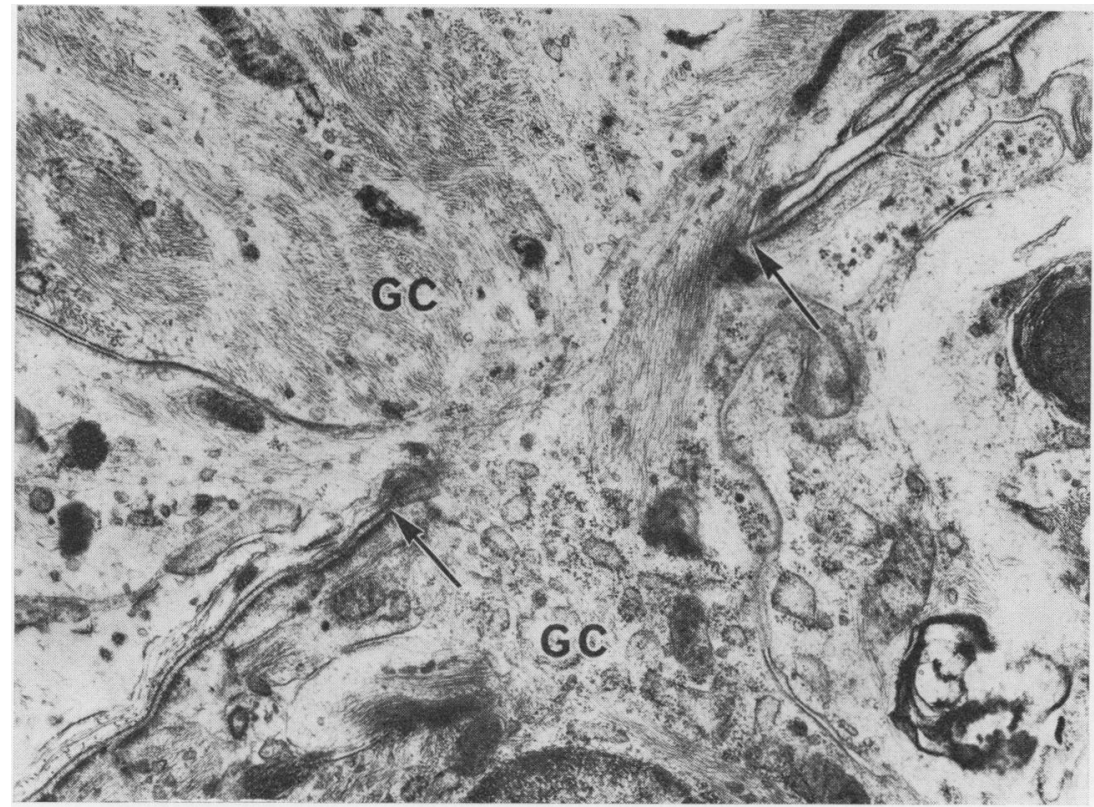

FIG. 9 Higher magnification of the area in Fig. 8, showing the break in the internal limiting membrane (arrows) and the cellular continuity of the glial cells $(G C)$ through the opening. $\quad \times 16,650$

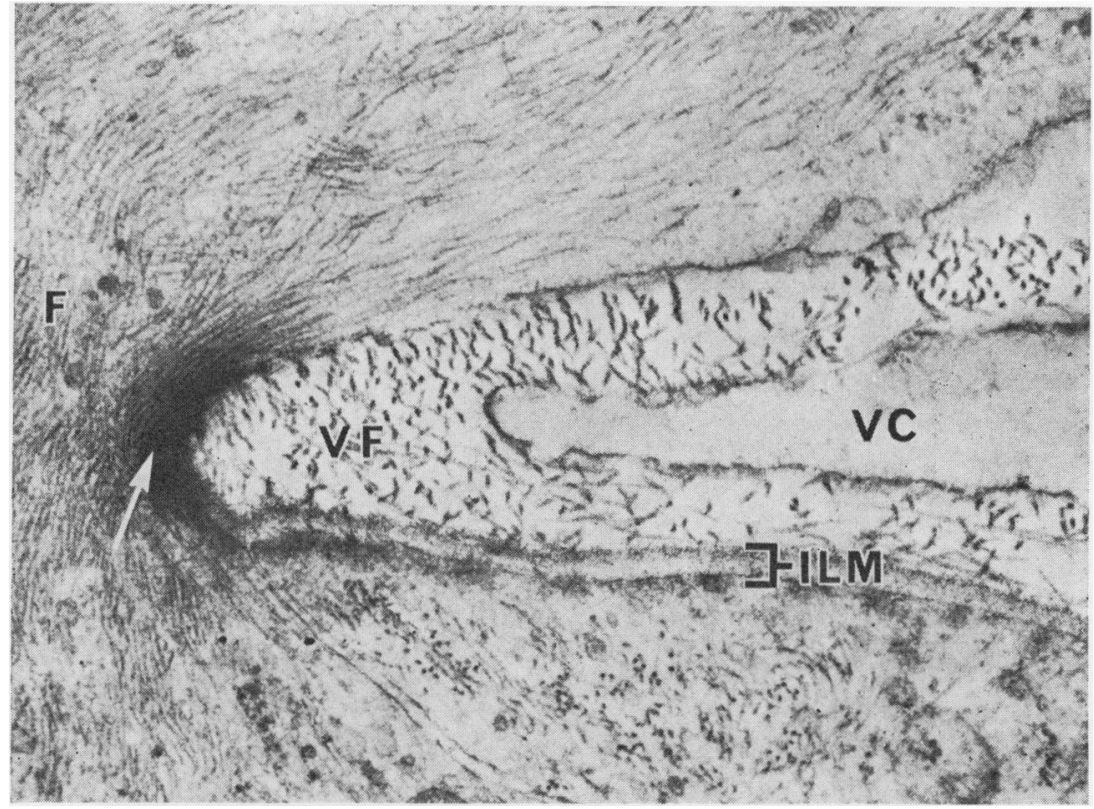

FIG. Io Electron micrograph of the opening in the internal limiting membrane (ILM), showing the arching and condensation (arrow) of the intracellular fibrils $(F)$ of the glial cell. $\times 50,000$

$\mathrm{VF}=$ vitreous fibrils $\quad \mathrm{VC}=$ pseudopod of a vitreal cell 


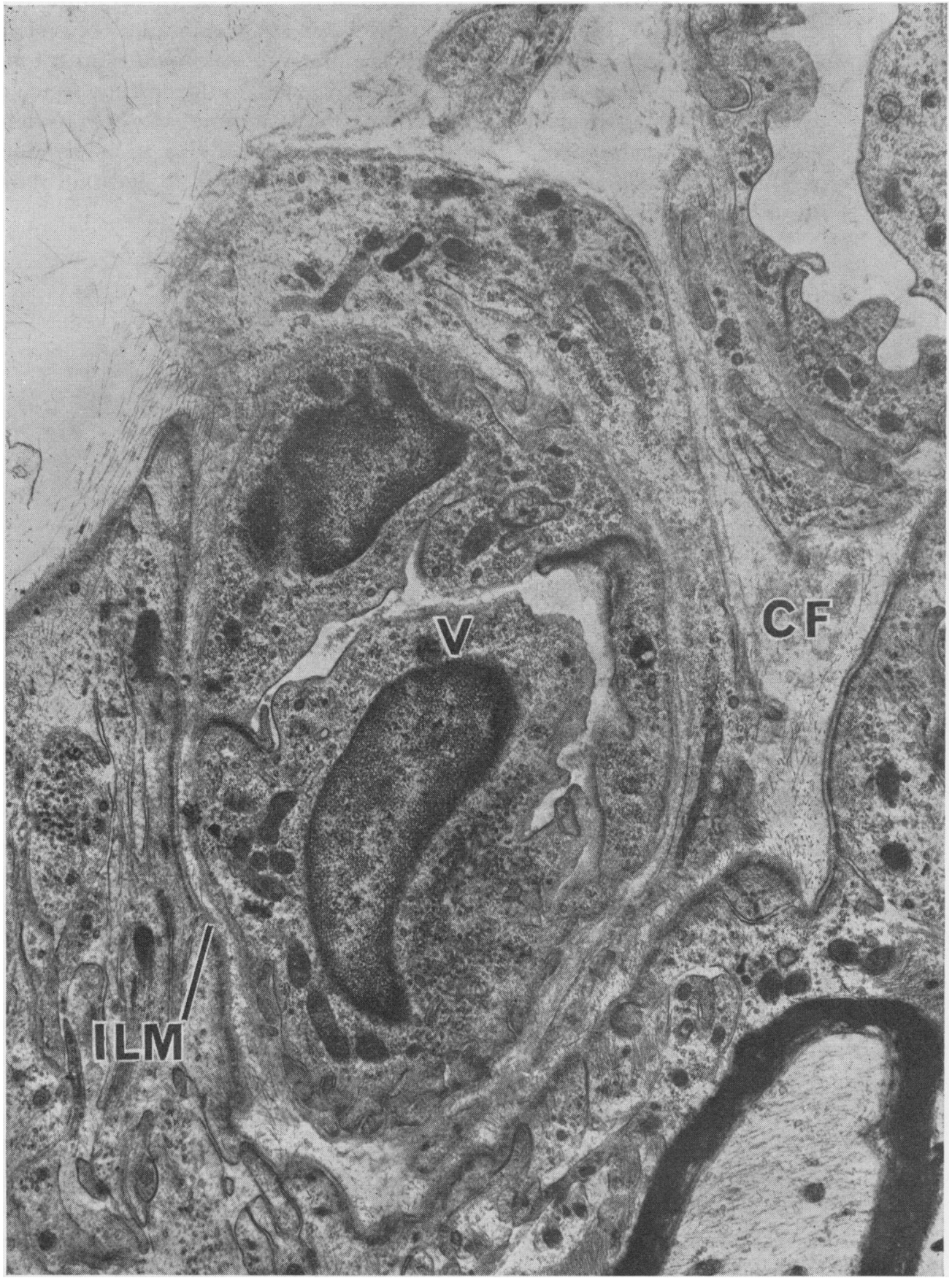

FIG. I I Electron micrograph, showing a blood vessel $(V)$ encupped within an invagination of the internal limiting membrane $(I L M) . \times 15,000$

$\mathrm{CF}=$ collagenous fibrils interposed between the internal limiting membrane and the basement membrane of the blood vessel 
It is clear that, while the superficial vessels in the main lie vitreal to the internal limiting membrane, free within the vitreous, their basement membranes occasionally lie directly upon the basement membrane of the internal limiting membrane, and at frequent intervals the vessels are anchored to the retinal surface by glial attachments, which protrude from the retina, often enclasping and sometimes almost completely surrounding the vessels. With this knowledge of the fine structure it was interesting to re-examine conventional paraffin sections stained with haematoxylin and eosin and to find that these glial attachments may readily be recognized (Fig. 12).

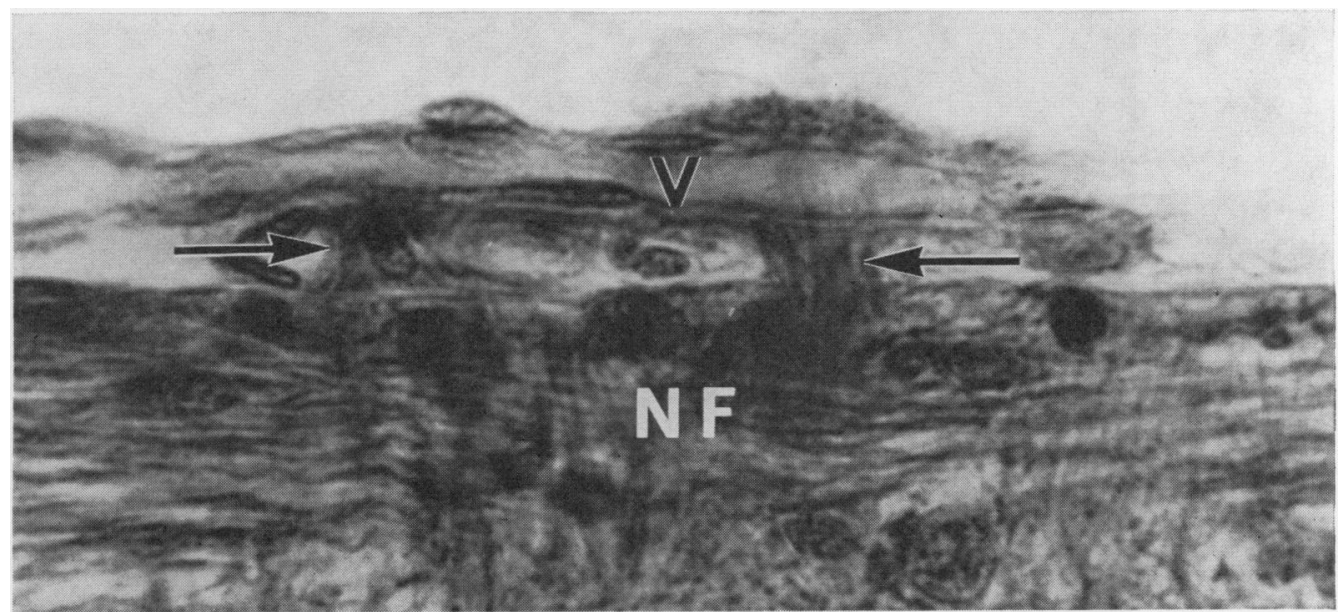

FIG. I2 Paraffin section of rabbit retina, showing glial protrusions (arrows) in contact with and surrounding a blood cessel $(\boldsymbol{V})$ cut longitudinally. Haematoxylin and eosin. $\times 800$

$\mathrm{NF}=$ nerve fibre layer

As we have shown, superficial vessels may occasionally appear to enter the retina, but actually they lie within invaginations of the internal limiting membrane from which they are separated by collagenous fibrils. In a subsequent paper providing a more detailed account of the rabbit's retinal vessels, we shall show that this is true also of the deep capillary branches which loop down into the nerve fibre layer so that in fact none of the vessels of the rabbit retina lies strictly within the nervous tissue. This vaso-glial structure corresponds with that described in the optic nerve of the monkey (Anderson, 1969, Fig. 4), which accords with the point made by Rohen (1954) that, since the medullated fibres of the rabbit are actually a forward extension of the optic nerve, the vessels are to be regarded as a vascular system of the nerve rather than of the retina.

At what developmental stage the glial tufts first appear has not yet been determined: they may exist before the vessels develop, or grow to embrace them as they proliferate along the retinal surface, or result from traction by the vessels at points where they were adherent to or were embedded in the retinal surface. Finally, it is interesting to note that similar glial tufts have been observed by conventional microscopy in cases of persistent hyperplastic vitreous (Hagedoorn and Sieger, I956; Manschot, I958) and by electron microscopy in experimental retrolental fibroplasia (Ashton, I968), but whether there is any relationship in their genesis is at present unknown.

We acknowledge with thanks a grant from the Medical Research Council which has enabled the above work to be carried out. We are also grateful to Miss Angela Stone for technical assistance and Miss E. FitzGerald for secretarial help. 


\section{References}

Agarwal, L. P., singh, K. T., and Dayal, Y. (1966) Orient. Arch. Ophthal., 4, 47

ANderson, D. R. (1969) Arch. Ophthal. (Chicago), 82, 800

Ashton, N. (1968) Brit. 7. Ophthal., 52, 505

- and OLIVEIRA, F. (1966) Ibid., 50, II9

BRUnS, L. (1882) Z. vergl. Augenheilk., 1, 77

eisler, P. (1930) "Die Anatomie des menschlichen Auges," in "Kurzes Handbuch der Ophthalmologie," ed. F. Schieck and A. Brückner, vol. I, p. I. Springer, Berlin

FUCHs, H. (1905) Anat. Hefte, abt. I, 28 (Heft 84), I (Arb. anat. Inst., Wiesbaden)

HAGedoorn, A., and SIEGer, D. H. (1956) Amer. J. Ophthal., 41, 660

HIS, w. (1880) Arch. Anat. Physiol. (Anat. Abteil), p. 224

HYVÄRINEN, L. (1967) Acta ophthal. (Kbh.), 45, 852

kUWABara, T., and COGAN, D. G. (1960) Arch. Ophthal. (Chicago), 64, 904

LANGENBACHER, L. (1880) Oest. Vjschr. wiss. Veterinarkünde, 53, $12 \mathrm{I}$

manschot, w. A. (1958) A.M.A. Arch. Ophthal., 59, 188

michaelson, I. c. (1954) "Retinal Circulation in Man and Animals", p. 29. Thomas, Springfield, Ill.

MUTLU, F., and LeOPOLD, I. H. (1964) Amer. F. Ophthal., 57, 804

ROHEN, J. (1954) Ophthalmologica (Basel), 128, 307

schultze, O. (1982) In "Festschrift. Herrn Geheimrat Albert von Koelliker", p. I. (Dedicated

by the Anatomische Institut der Universität Würzburg.) Engelmann, Leipzig 